\title{
DISPUTA ENTRE LOS CONSULADO DE CÁDIZ Y MÉXICO POR LOS MERCADOS DE NUEVA ESPAÑA. FINES DEL SIGLO XVII Y PRIMERAS DÉCADAS DEL SIGLO XVIII
}

\author{
Guillermina Del Valle Pavón \\ INSTITUTO DE INVESTIGACIONES \\ Dr. José Ma Luis Mora (MéXico)
}

\begin{abstract}
RESUMEN
A partir de las últimas décadas del siglo XVII la monarquía hispana se propuso regularizar la Carrera de Indias. Para acortar la estancia de las flotas en Nueva España mandó celebrar una feria el puerto de Veracruz, la cual fracasó debido a los conflictos que los cargadores andaluces y los mercaderes de México tenían por el establecimiento de los precios y el acceso de los primeros a los mercados del virreinato. Una vez que se estableció la feria en de Jalapa, cerca de Veracruz, los Consulados de México, Cádiz y Sevilla negociaron con las autoridades reales la modificación de las normas de la Carrera de Indias en beneficio de sus respectivos intereses.
\end{abstract}

PALABRAS CLAVE: comercio Atlántico, consulados, mercaderes, precios, México, Cádiz.

\section{ABSTRACT}

The Spanish crown aimed to regulate the Carrera de Indias (Indies trade) in the last decades of the 17th century. To shorten the time spent by the fleets in New Spain, the crown ordered the holding of a fair in the port of Veracruz. The fair failed due to conflicts between Andalucian traders and the merchants of Mexico City: they disputed price-setting and the entrance of the first group to the viceroyalty markets. Once the fair was established in Jalapa, nearby Veracruz, the merchant guilds of Mexico, Cadiz and Seville negotiated modifications in the rules of the Indies trade with royal authorities, to benefit their own interests.

KEY WORDS: Atlantic trade, merchant guilds, merchants, prices, Mexico, Cadiz. 
En las últimas décadas la historiografía sobre el comercio Atlántico ha cuestionado la tesis relativa al dominio que ejerció la monarquía Hispánica sobre los reinos de Indias. En el caso de Nueva España observamos cómo los mercaderes que integraban el Consulado de la ciudad de México, durante el siglo XVII habían adquirido una gran autonomía financiera y mercantil. Esto se explica por el control que ejercían sobre la producción y circulación de la plata, el cual les permitió dominar el comercio triangular del Pacífico y promover el contrabando que se realizaba con las potencias marítimas que disputaban al Imperio Español el monopolio del tráfico Atlántico. El objetivo del presente artículo radica en examinar cómo los intentos de la corona por regular la Carrera de Indias se vieron se vieron obstaculizados por los conflictos que había entre los cargadores andaluces y los miembros del Consulado de la ciudad de México. Los comerciantes de Cádiz y Sevilla tenían la política de abastecer al virreinato de manera restringida con el propósito de imponer los precios más elevados, sin embargo, los almaceneros, como se llamaba a los mercaderes de México, se resistían a pagarlos.

A continuación se examinan los enfrentamientos que hubo entre ambos comercios en torno al establecimiento de los precios de las mercancías europeas y el acceso de los flotistas a los mercados del interior de Nueva España. Veremos la forma en que el Consulado de México logró que los virreyes le dieran su respaldo frente a los cargadores andaluces, mientras que el cuerpo mercantil gaditano contó con el apoyo de los ministros de las instituciones de Indias. Las normas introducidas para el establecimiento de ferias en las que los precios se acordaran de manera corporativa fueron renegociadas en diversas ocasiones por los representantes de ambos comercios, debido a la imposibilidad de alcanzar un acuerdo que los dejara satisfechos. En el periodo que abordamos los mercaderes de México tuvieron mayor capacidad de negociación porque el control que ejercían sobre la plata les permitía articular los flujos mercantiles del Atlántico y el Pacífico, mientras que la administración de la renta de alcabalas les dio un gran poder financiero.

\section{El comercio de la Carrera de Indias y Nueva España a fines de siglo XVII}

El comercio de la Carrera de Indias que monopolizó el tráfico de España con sus posesiones hispanoamericanas empezó a decaer en la década de 1620. A partir de entonces el comercio legal presentó una contracción progresiva que se agudizó al final del siglo XVII. Al tiempo que se reducía el envío de caudales privados de Nueva España a la Metrópoli, aumentaba su arribo a los puertos de las potencias europeas, como resultado del contrabando ${ }^{1}$. La demanda novohispana de textiles y otros productos europeos era satisfecha por holandeses, franceses, ingleses, entre otros europeos, que traficaban en las flotas de manera ilícita y realizaban comercio intérlope en Hispanoamérica desde las Antillas. Por su parte, los cargadores peninsulares que operaban por su cuenta o fungían como intermediarios de los extranjeros, también comerciaban de manera ilegal

\footnotetext{
1 Véase al respecto, MORINEAU, Michel, Incroyables gazettes et trésors merveilleux. Les retorus des trésors américains d’aprés les gazettes hollandaises (XVIe-XVIIIe siécles), Londres, Cambridge University Press / Paris, Editions de la Maison des Sciences de l'Homme 1985; ROMANO, Ruggiero, Coyunturas opuestas: la crisis del siglo XVII en Europa e Hispanoamérica, México, Fondo de Cultura Económica, Fideicomiso Historia de las Américas, 1993, pp. 129-138.
} 
para evadir el pago de derechos aduanales y extraer la plata americana fuera de registro. En esta forma ponían a salvo de las confiscaciones que practicaba la corona cuando requería de caudales para financiar sus guerras u otras urgencias. Los mercaderes de la ciudad de México también participaban en el tráfico ilícito al que destinaban los metales que no habían pagado los derechos reales. En esta forma obtenían ganancias muy elevadas, porque, además, evadían el pago de la alcabala y el almojarifazgo que se imponían a la circulación de mercancías².

En el marco de la formación histórica del mercado mundial las potencias europeas penetraron la Carrera de Indias como parte de un proceso de expansión mercantil. Al término de la guerra de los Treinta Años, la corona se había visto obligada a firmar una serie de tratados bilaterales de comercio con las naciones europeas más poderosas, circunstancia que socavó sus barreras proteccionistas. Verificada la paz con Holanda, en 1650, Felipe IV tuvo que concederles una serie de privilegios comerciales y fiscales. Así fue como los holandeses se establecieron en España, en colonias autónomas regidas por un cónsul y con su propio tribunal mercantil; los navieros fueron autorizados a transportar mercancías a Cádiz y sus embarcaciones fueron exceptuadas de la visita de fondeo en las aduanas, lo que facilitó los transbordos ilegales. Cuando se pactó la paz con Francia, en 1659, la corona tuvo que otorgarle concesiones similares, como sucedió con Gran Bretaña en $1667^{3}$. En esos años se puso de manifiesto el fin de la hegemonía que España había detentado en Europa, frente a la supremacía que habían adquirido Holanda, Francia y Gran Bretaña.

La incapacidad de España para abastecer los mercados de Indias había dado lugar a la participación de comerciantes de las principales economías manufactureras de Europa desde que se inició el comercio con Nueva España ${ }^{4}$. A raíz de que los negociantes de las potencias del norte de Europa se asentaron en Cádiz, se reforzó el papel que los españoles desempeñaban como distribuidores de las mercancías europeas en Indias. Los mercaderes de Sevilla y Cádiz que no contaban con grandes capitales para adquirir por su cuenta las manufacturas en los puertos europeos, las compraban a crédito a las casas extranjeras de importación. Estas les otorgaban crédito para adquirirlas y transportarlas, operación que, en condiciones óptimas, les rendían a dividendos que fluctuaban entre el 30\% y el 50\%, cuando menos. Las ganancias de los extranjeros eran mucho mayores cuando utilizaban a los cargadores españoles como agentes por comi-

2 VALLE PAVÓN, Guillermina del, "Bases del poder de los mercaderes de plata de la ciudad de México. Redes, venalidad, control del consulado y la casa de moneda a fines del siglo XVII”, Anuario de Estudios Americanos, 2011.

3 En 1667, España tuvo que reconocer la conquista de Jamaica por parte de Inglaterra. DELGADO RIVAS, José María, Dinámicas imperiales [1650-1796]. España, América y Europa en el cambio institucional del sistema colonial español, Barcelona, Ediciones Bellaterra, 2007, pp. 56, 57. DOMÍNGUEZ ORTÍZ, Antonio, "La burguesía gaditana y el comercio de Indias desde mediados del siglo XVII hasta el traslado de la casa de contratación”, en La burguesía mercantil gaditana (1650-1868), Cádiz, Instituto de Estudios Gaditanos, Excma. Diputación Provincial de Cádiz, 1976, p. 4; LYNCH, John, España bajo los Austrias. 2. España y América (1598-1700), Barcelona, Ediciones Península, [1º. ed. en español 1970], 1988, v. II, pp. 172, $221-222$. 4 STUDNICKI-GIZBERT, Daviken, "From Agents to Consulado: Comercial Networks in Colonial Mexico, 1520-1590 and Beyond”, Anuario de Estudios Americanos, v. LVII, (1), 2000, pp. 46, 48; VALLE PAVÓN, Guillermina del, “Orígenes de la centralidad comercial de la ciudad de México en el siglo XVI”, en Lourdes de Ita (coord.), Organización del Espacio en el México Colonial: Puertos, Ciudades y Caminos, México, Universidad Michoacana de San Nicolás de Hidalgo, Instituto de Investigaciones Históricas, 2010. 
sión dándoles los géneros en consignación, de manera ilegal, para que los vendieran en Nueva España ${ }^{5}$.

La decadencia creciente de los intercambios legales de la Carrera de Indias se profundizó a partir de la década de $1680^{6}$. En Nueva España se incrementó la producción de plata y la consiguiente demanda de bienes externos, la cual fue satisfecha por los contrabandistas europeos y a través del comercio con Filipinas. Holanda e Inglaterra, que se habían apoderado de varias islas de las Antillas en la primera mitad del siglo $\mathrm{XVII}^{7}$, en la década de 1680, desplazaron a los piratas al establecer grandes bodegas y almacenes, principalmente en Jamaica y Curazao, desde donde empezaron a realizar comercio intérlope en Hispanoamérica valiéndose de pequeños navíos ${ }^{8}$.

Por otra parte, el comercio triangular del Pacífico -entre Acapulco, Manila y El Callao- que se encontraba bajo el control de los mercaderes de México ${ }^{9}$ se reactivó en la década de $1680^{10}$. Este fenómeno fue consecuencia del aumento de la producción de plata, el restablecimiento del abasto de azogue peruano a Nueva España y el fortaleci-

5 STEIN, Stanley J. y Barbara H. STEIN, Plata, comercio y guerra. España y América en la formación de la Europa moderna, Barcelona, Crítica, 2000, pp. 28, 29; BUSTOS RODRÍGUEZ, Manuel, Cádiz en el sistema Atlántico. La ciudad, sus comerciantes y la actividad mercantil (1650-1830), Madrid, Sílex Ediciones, Universidad de Cádiz, 2005, pp. 138-184, 355-372. DELGADO RIVAS, Op. Cit., pp. 57-59.

6 Según los datos sobre las “importaciones” legales de caudales del virreinato en la segunda mitad del siglo XVII, el ingreso de maravedíes procedentes de América a la Península en la década de 1690, se redujo en un $272 \%$ con respecto al decenio de 1670 , y con relación a la década de 1650, en la que se presentaron las mayores entradas de fondos del periodo, cayó en cerca de 300\%. García Fuentes, 1980, pp. 379-383, 387-399, 399. La caída que presentó el comercio español con América puede apreciarse con gran claridad en la gráfica sobre el "movimiento general de toneladas de arqueo en navíos mercantes y tendencia lineal”, 1650-1700, que presenta el mismo autor. Ibídem. Gráfico 7, p. 234.

7 Los holandeses habían tomado Guayana (Fort Nassau) en 1624, Curazao, Bonaire y Aruba, entre 1621 y 1640; los ingleses Guyana en 1595, San Cristóbal, Santa Lucía y Jamaica, entre 1610 y 1655; y los franceses Martinica y Guadalupe en 1635, Tortuga en 1640, Cayena en 1650 y Haití en 1655. ROMANO, Ruggiero, Mecanismo y elementos del sistema económico colonial americano. Siglos XVI-XVIII, México, Fondo de Cultura Económica, 2004, p. 282.

8 MACLEOD, Murdo J. “España y América: el comercio Atlántico, 1492-1720”, en Leslie Bethell, editor, Historia de América Latina. 2. América Latina colonia: Europa y América en los siglos XVI, XVII, XVIII, Barcelona, Editorial Crítica, v. 2, 1990, pp. 76- 79.

9 El tráfico que se realizaba entre los virreinatos de Perú y Nueva España se prohibió en 1620 debido a que el intenso comercio de bienes orientales propiciaba la salida de plata hacia el Oriente. Las transgresiones a dicha proscripción dieron lugar a que el real mandato se reiterara en 1634 y 1636, sin embargo, los intercambios sólo pudieron suspenderse a raíz de las medidas que tomó el visitador Pedro de Quiroga, con el apoyo del virrey marqués de Cadereytia. Acerca del comercio Pacífico véase VALLE PAVÓN, Guillermina del, "Los mercaderes de México y la transgresión de los límites al comercio Pacífico en Nueva España, 1550-1620”, en Revista de Historia Económica, La Economía en tiempos del Quijote, v. XXIII, número extraordinario, Madrid, 2005, pp. 213-240.

10 Contamos, entre otras, con las siguientes evidencias: la investigación que promovió la audiencia de México en 1696 sobre el envío de grandes cantidades de plata a Acapulco para comerciar en Filipinas. En 1697, arribó a Acapulco un navío procedente del virreinato andino, cuya tripulación y pasajeros, principalmente comerciantes, traían “dos millones de pesos de a ocho, para emplearlos en mercancías de China”. AGN, AHH, 218-25. El aumento del tráfico legal e ilícito que realizaba la Nao de Manila se hace patente con la tendencia ascendente que presentó el cobro del almojarifazgo de Filipinas de la década de 1690 hasta 1720. CHAUNU, Pierre, Las Filipinas y el pacífico de los ibéricos siglos XVI-XVII-XVIII. (estadísticas y atlas), México, Instituto Mexicano de Comercio Exterior, 1976, pp. 107, 110, 111. 
miento económico y político de los mercaderes de México ${ }^{11}$. El conde de Galve, que fue virrey de Nueva España entre 1688 y 1696, fue acusado de participar en el contrabando que efectuaban los peruleros al adquirir los bienes de la flota y el galeón de Manila con plata andina ${ }^{12}$. En 1699 el fiscal de la Audiencia de Lima denunció ante el Consejo de Indias "la frecuencia del comercio de este reino con el de Nueva España e introducción de géneros de China”13. En 1702 se mandó al virrey que no se quebrantaran las prohibiciones comerciales, acerca de lo cual se debía dar testimonio al Consulado de Méxi$\mathrm{Co}^{14}$. Entonces Nueva España se había transformado en el centro de una red de flujos comerciales, legales e ilícitos, que articulaba el tráfico de bienes orientales y europeos, los cuales eran objeto de una gran demanda en los virreinatos americanos, así como en Guatemala, las Antillas y Venezuela ${ }^{15}$.

\section{Conflictos entre los consulados de México y Cádiz}

En las últimas décadas del siglo XVII y las primeras del siglo XVIII la corona se propuso regularizar la Carrera de Indias, con el objeto de asegurar los ingresos aduanales del erario y limitar el contrabando. El Consejo de Indias pretendía que las flotas zarparan cada año, mientras que el Consulado de Cargadores de Indias se esforzaba por reducir la frecuencia de las salidas y el volumen de los cargamentos a fin de que la demanda insatisfecha propiciara la elevación de los precios. Para normalizar las flotas también era necesario acortar la estancia de los comisionistas peninsulares en Nueva España. Los flotistas permanecían varios meses en el virreinato por las pugnas que enfrentaban con los mercaderes de la ciudad de México para establecer los precios de los bienes europeos. Por tal motivo, las autoridades reales se esforzaron por regular las negociaciones que llevaban a cabo los comercios de Andalucía y México en relación con la compra-venta de mercancías.

Los mercaderes participaban en la Carrera de Indias como encomenderos de los cargadores andaluces y por su propia cuenta. Cuando fungían como agentes por comisión de las empresas arraigadas en Sevilla y Cádiz, solicitaban las mercancías de mayor demanda para expenderlas en el virreinato a cambio de una comisión, a la que agregaban otros beneficios. Las relaciones entre los mercaderes de México y Andalucía se basaban en la confianza y, en algunos casos, en lazos familiares y de paisanaje, ya que la mayor parte de los almaceneros eran originarios de la península Ibérica, en particular de las provincias del norte. Los mercaderes de México también compraban por su

11 VALLE PAVÓN, “Bases del poder”.

12 Dicha acusación no pudo comprobarse. GUTIÉRREZ LORENZO, "La real hacienda en la época del conde de Galve, 1688-1696”, en Novahispania, núm. 2, Instituto de Investigaciones Filológicas, Seminario de Cultura Novohispana, UNAM, 1995, pp. 372, 373.

13 GARCÍA-FUENTES, Lutgardo, Los peruleros y el comercio de Sevilla con las Indias, 1580-1630, Sevilla, Universidad de Sevilla, 1997, p. 169.

14 Real cédula dada en Madrid el 18 de julio de 1702. AGN, AHH, 599-3.

15 BONIALIAN, Mariano, “México epicentro semi-informal del comercio hispanoamericano (1680-1740)”, América Latina en la Historia Económica Revista de Investigación, México, no. 35, enero-junio de 2011. Véase también el testimonio que en 1702 dio SEIJAS Y LOBERA, Francisco, Gobierno militar y político del Reino Imperial de la Nueva España (1702), México, Universidad Nacional Autónoma de México, 1986, p. 455. 
propia cuenta los bienes europeos que arribaban en las flotas, los cuales saldaban principalmente con plata en moneda y en pasta y, de manera secundaria, con tintes, cacao de Guayaquil, cueros y otros productos americanos. La posición de los mexicanos era favorecida por su asociación en el Consulado de la ciudad de México, corporación que representaba los intereses de sus miembros y monopolizaba el ejercicio de la justicia mercantil en Nueva España.

A petición del Consulado de Cargadores de Indias, en 1670 el rey ordenó que los comandantes de las flotas, en cuanto llegaran a Veracruz mandaran un navío de aviso a Sevilla para que informara acerca del precio de las mercaderías, su escasez o abundancia, con el objeto de prevenir la carga del siguiente convoy ${ }^{16}$. Los andaluces se esforzaban por conocer las condiciones de la demanda en Nueva España para que el abasto de la flota fuera conveniente.

En 1679, la determinación de la corona a enfrentar la decadencia del tráfico Atlántico y el predominio de los extranjeros, la condujo a instituir la Junta de restablecimiento del comercio. Entre las reformas que realizo la junta se destaca el traslado de la cabecera de las flotas al puerto de Cádiz, aun cuando la Casa de Contratación y el Consulado de Indias se mantuvieron en Sevilla ${ }^{17}$. Para conseguir que las flotas zarparan cada año, era necesario que no permanecieran largos periodos en Nueva España, en espera de que se vendieran las mercancías. A fin de lograr el pronto regreso de los convoyes, la junta propuso que los comercios de Andalucía y México realizaran una feria en el puerto de Veracruz en la que negociaran de manera corporativa los precios de los bienes europeos.

A través del establecimiento de la feria las autoridades también atendían las quejas del Consulado de Cargadores de Indias sobre la forma en que los mercaderes de México maniobraban para abaratar las mercancías. La corporación había planteado que, una vez que los mexicanos conocían con todo detalle la calidad de los productos "se ajustan a comprar [a] los precios que ellos quieren y confieren, deteniéndose en la compra y esperando a que la abundancia de un género obligue a venderlo al precio que

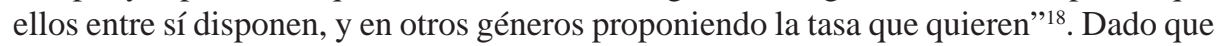
la política de abasto de los andaluces consistía en brindar una oferta limitada a los precios más elevados, buena parte de la demanda era satisfecha con los bienes orientales y los que se introducían a través del contrabando. En consecuencia, los almaceneros, como se llamaba a los mercaderes de México, podían presionar a los flotistas para que redujeran los precios.

En 1683 el monarca ordenó realizar la feria de la flota en Veracruz. Los diputados de los comercios de España y México debían congregarse en el puerto, con la participación de las autoridades del virreinato y el comandante del convoy para llegar

16 Extracto de la real cédula fechada en Lerma, 19 de junio de 1670. AGN, AHH- (México), 599-3.

17 GARCÍA-FUENTES, Lutgardo, El comercio español con América 1650-1700, Sevilla, Excma. Diputación Provincial de Sevilla / Escuela de Estudios Hispanoamericanos, CSIC, 1980, pp. 104-109; KUETHE, Allan J., “Traslado del consulado de Sevilla a Cádiz: nuevas perspectivas”, en Enriqueta Vila Vilar y Allan J. Kuethe (eds.), Relaciones de poder y comercio colonial: nuevas perspectivas, Sevilla, Escuela de Estudios Hispanoamericanos / Texas-Tech University, 1999, p. 67.

18 Citado en BERNAL, Miguel Antonio, La financiación de la Carrera de Indias (1492-1824). Dinero y crédito en el comercio colonial español con América, Sevilla, Fundación El Monte, 1992, p. 224. 
a un acuerdo sobre los precios. Con base en el convenio realizado se debería "abrir y celebrar feria y comprar hasta en cantidad de 100,000 pesos, y que lo referido sirva de ejemplar a todo el reino”19. Poco después de que la flota arribó a Veracruz, los comisionados de los cargadores españoles presentaron una memoria con los precios de 174 mercancías. Los apoderados de México hicieron una primera contraoferta de precios que, en promedio, equivalía al 48\% de la propuesta presentada por los peninsulares, por lo que fue rechazada. Así se presentaron hasta ocho contraofertas, la última de las cuales ascendió, en promedio, al 63\% de proposición inicial. Al cabo de quince días de fracasos se suspendieron las negociaciones ${ }^{20}$, y los flotistas llevaron sus mercancías a la ciudad de México para venderlas ${ }^{21}$.

Durante la Guerra de Sucesión Dinástica los franceses tomaron el control de la Junta de Restablecimiento de Comercio. Con la intención de favorecer el contrabando que realizaban sus compatriotas en Nueva España aplazaron la partida de la flota ${ }^{22}$. Finalmente, en 1706 el convoy con diecisiete bajeles arribó a Veracruz, más de cinco años después de la llegada del anterior. El Virrey duque de Alburquerque mandó realizar una feria en el mismo puerto para agilizar el retorno del convoy. El Consulado de México, luego de nombrar a sus diputados para negociar en la feria, informó al virrey que los comisionistas peninsulares no parecían estar dispuestos a llegar a un acuerdo, porque habían empezado a contratar en Veracruz y a transportar mercancías al interior del virreinato. Reunidos en Veracruz los delegados de ambos comercios, los andaluces hicieron una propuesta de precios, a la que los mexicanos plantearon una contraoferta que equivalía, en promedio, al 50 y el 60\%. Poco después se rompieron las negociaciones. Ante la protesta del comandante de la flota por la posición de los representantes del Consulado de México, el virrey lamentó que los peninsulares los hubieran rechazado, porque en el interior no podrían conseguir mejores precios y mandó que el convoy se despachara de acuerdo con lo planeado ${ }^{23}$. No obstante, el tornaviaje se pospuso de manera indefinida, debido a que una escuadra inglesa compuesta por dieciocho navíos esperaba sorprender a la flota en Jamaica y Barbados ${ }^{24}$. El duque de Alburquerque se manifestó a favor de los almaceneros porque requería de su respaldo financiero para contribuir con las campañas bélicas de Felipe $\mathrm{V}^{25}$.

Poco después de que los peninsulares empezaron a vender en la ciudad de México, el consulado denunció ante el virrey que los flotistas habían aumentado los precios

19 Citado en Idem.

20 Ibídem, pp. 224-226, en especial el cuadro situado en la p. 226.

21 Representación del Consulado de México, 15 de mayo de 1725 (AGN, AHH, 269-2).

22 KAMEN, La Guerra de Sucesión en España, 1700-1715, Barcelona, Grijalbo, 1974, pp. 166-167; WALKER, Geoffrey J., Política española y comercio colonial, 1700-1789, Barcelona, Editorial Ariel, 1979, pp. 39-56, 75-77.

23 Autos sobre la flota de 1706. Archivo General de Indias -en adelante, AGI- (Sevilla), 477, fs 591-761.

24 Real cédula de 27 de julio de 1707. AGI, México, 479, fs. 5-14.

25 Véase al Respecto VALLE PAVÓN, Guillermina del, "El respaldo económico del Consulado de México para la Guerra de Sucesión Dinástica”, en Antonio Acosta Rodríguez, Adolfo González Rodríguez y Enriqueta Vila Vilar, coordinadores, La Casa de la Contratación y la navegación entre España y las Indias, Sevilla, Universidad de Sevilla; Consejo Superior de Investigaciones Científicas, Escuela de Estudios Hispanoamericanos, Fundación El Monte, 2004, pp. 941-964. 
del hierro, el azafrán, el papel y el aceite “sin proporción, ni medida”. Que “no contentos con haber ganado en sus primeras ventas doscientos y más por ciento habían bajado a la Veracruz a hacer nuevos empleos para revender, conciliándose con otros para ir cada día subiendo los precios, ocultando a este fin y estancando los géneros”. Los mineros también se habían quejado por el elevado precio al que había llegado el hierro, que no podían pagar y era indispensable para sus labores, por lo que el virrey había remitido el caso al fiscal y convocado a Real Acuerdo para discutirlo. Ante la alarma que se produjo, los comisionistas españoles moderaron los precios, por lo que no hubo necesidad de proceder por la vía judicial. El virrey consultó al monarca, quien, con base en el dictamen del Consejo de Indias, planteó que los comerciantes podían tener lucro o ganancia del 200 ó 300\% en un género o especie, porque en otros podían no ganar nada o sufrir pérdidas, pero reprobó que de ello hicieran "convenciones o monopolios” en perjuicio de la común utilidad ${ }^{26}$.

Los comisionistas peninsulares tenían especial interés en internarse en Nueva España para intercambiar los bienes europeos por plata ${ }^{27}$, géneros orientales, cacao de Guayaquil, tintes y otros productos. En la ciudad de México también podían acceder a la plata andina, en razón de que comerciantes limeños acudían a la capital virreinal en busca de géneros castellanos, europeos y asiáticos. En 1706 el consulado de Lima informó a la real Hacienda que el principal obstáculo para realizar la feria de Portobelo era el abastecimiento de bienes europeos desde México. Con respecto a la flota que había llegado en dicho año a Veracruz el cuerpo mercantil limeño planteó que su carga era mayor de la que podía consumirse en México y aseveró que “de las memorias que compraren los mercaderes de aquel reino y de las que no vendieron los cargadores de España pasarán a éste [Perú] la mayor parte" ${ }^{28}$, Cuando el siguiente convoy arribó a Veracruz, en 1708, hubo un nuevo intento infructuoso de celebrar la feria en el puerto $^{29}$, por lo que los flotistas se dirigieron nuevamente a la ciudad de México a vender sus mercaderías. En esta ocasión el virrey duque de Alburquerque también apoyó a los mercaderes Consulado de México, quienes había reunión un empréstito por un millón de pesos para satisfacer las urgencias que entonces enfrentaba el monarca ${ }^{30}$.

El duque de Alburquerque también había pedido capitales a crédito a los diputados del comercio de España, quienes se habían disculpado de contribuir al préstamo porque los capitales de que disponían pertenecían a "los que quedaron en España y arriesgaron sus intereses”, por lo que disponer de ellos sería "faltar a su confianza y exponerse a que... procediesen contra sus personas”. Los cargadores andaluces tenían

26 La misma real cédula se publicó el 22 de junio de 1709 y el 22 de noviembre de 1710. AGN, AHH, 326, fs. 117,118 y $599-3$.

27 En 1663, el oidor de la audiencia, Calderón y Romero, ante el incremento de la extracción de plata que no había pagado derechos, había planteó que, cuando los mineros eran sorprendidos transportando la plata que carecía de la marca correspondiente alegaban que se dirigían a la ciudad de México para pagar los gravámenes, no obstante, vendían los metales a los tratantes de las flotas de manera clandestina. (El subrayado es mio). BAKEWELL, Peter J., Minería y sociedad en el México Colonial. Zacatecas (1546-1700), México, Fondo de Cultura Económica, 1976, p. 254.

28 BONIALIAN, Op. Cit.

29 Representación del Consulado de México, 15 de mayo de 1725. (AGN, AHH, 269-2).

30 VALLE PAVÓN, “Respaldo”, 2004. 
motivos para negarse a colaborar con la demanda del virrey. Por una parte éste había apoyado la propuesta de los mercaderes de México, que había llevado a la cancelación de la feria en Veracruz y, por otra, el monarca había secuestrado los caudales de la flota que había sido forzada a arribar al puerto de Vigo en 1702, medida que, como vimos, los había hecho perder cerca de seis millones de pesos. De hecho, el diputado del comercio de España hizo referencia a una real cédula en la que Felipe V había prometido que "por ningún accidente... se valdría de ninguna cantidad por vía de donativo, ni empréstito”, para alentar al comercio de Sevilla y Cádiz a invertir sus caudales en la siguiente flota. ${ }^{31}$.

Concluida la guerra, las autoridades reales se esforzaron porque las flotas salieran rumbo a Nueva España cada año, con el propósito de aumentar el volumen del tráfico, generar mayores ingresos fiscales y disminuir el tráfico ilícito. Uno de los principales obstáculos para normalizar el calendario de la flota era su retención en el virreinato, debido a que los encomenderos españoles se internaban a comerciar en la ciudad de México y otros lugares del virreinato, lo que dilataba su regreso al puerto de Veracruz. De acuerdo con el virrey duque de Linares (1711-1716), los factores españoles no regresaban a Veracruz cuando la flota tenía que retornar por dos razones. En primer lugar, porque penetraban en el virreinato para intercambiar sus mercancías por plata que no había sido gravada o a la que sólo se le había descontado el derecho del diezmo. $\mathrm{Y}$, en segundo lugar, porque los almaceneros retrasaban las compras con el propósito de presionar a los factores peninsulares para que bajaran los precios. El duque afirmaba que los encomenderos iban a Nueva España "con intención de llevarse, si pudieran, el reino, y los habitantes en la de resistirla, discurriendo que sitiándolos con la necesidad les han de obligar a que dejen la ropa al precio más ínfimo que pueden”32.

Para los almaceneros que, como vimos, dominaban el comercio oriental ${ }^{33}$ y tenían una participación central en el contrabando, resultaba poco atractiva la compra de los géneros europeos que llegaban en las flotas a precios elevados, debido a la intermediación y al pago de derechos. En 1711 y 1712 las flotas arribaron a Veracruz poco después que los navíos franceses con licencia para comerciar, por lo que realizaron estancias prolongadas en Veracruz ${ }^{34}$. En consecuencia, en 1713 el Consulado de México demandó al rey que los convoyes se despacharan cada dos años y advirtió que si no se llevaba a cabo dicha medida el comercio no podría habilitar a la industria minera ${ }^{35}$. El Consejo de Indias realizó una consulta sobre dicha propuesta. De acuerdo con el Consulado de Sevilla, la provisión de flotas cada dos o tres años requería de enormes caudales, de los que carecían sus miembros, mientras que al suspenderlas se fomentaba

31 Juntas de comercio sobre el empréstito de un millón de pesos 1706. AGN, AHH, 213-9. VALLE PAVÓN, "Respaldo", 2004.

32 "Relación dada por el excmo. señor duque de Linares...”, en Instrucciones y memorias de los virreyes novohispanos, Estudio preliminar, coordinación, bibliografía y notas, México, Editorial Porrúa, 1991, tomo II, pp. 787- 788.

33 A partir de la década de 1690 el comercio oriental adquirió relevancia creciente, como indica la tendencia ascendente que mantuvo el cobro del almojarifazgo de Filipinas hasta 1720. CHAUNU, Op. Cit., pp. 107, $110,111$.

34 WALKER, Op. Cit., pp. 81-85.

35 “Representación del Consulado de México al virrey duque de Linares de 1713”, AGI, México 2501. 
el contrabando. Explicó que en Nueva España abundaban los géneros que llevaban las flotas, los extranjeros y la nao de Filipinas, todo lo cual era imposible consumir, por lo que los precios se reducían y gran parte de las mercancías se reexpedían a Perú ${ }^{36}$. En oposición a esta postura, las juntas de comerciantes de Cádiz, Santa María y Sanlúcar apoyaron la demanda del Consulado de México de espaciar las flotas, a condición de que se combatiera el contrabando ${ }^{37}$. A los comercios de México y Cádiz les convenía espaciar la salida de las flotas, a los primeros debido a su participación en el comercio ilícito y a los gaditanos para conseguir que sus mercancías se tasaran a precios mayores.

El problema entre los mercaderes de México y los peninsulares se profundizó a raíz de la entrada legal de los ingleses en el mercado novohispano. Como parte de los Tratados de Utrecht de 1713, Felipe V tuvo que conceder a Gran Bretaña el asiento para abastecer esclavos africanos a Hispanoamérica y permiso para enviar a Veracruz un navío anual de 500 toneladas, cuya carga se vendería a la llegada de la flota. El navío británico favoreció el contrabando y restó competitividad a las mercancías de los factores peninsulares, porque los géneros ingleses eran entre 25 y 30\% más baratos, entre otras razones, porque estaban exentos del pago de gravámenes. En 1715 la flota tuvo que regresar a Cádiz sin que se hubieran vendido gran parte de las mercancías, las cuales quedaron al cuidado de los factores peninsulares ${ }^{38}$. El duque de Linares, al igual que sus antecesores, había establecido una estrecha relación con los representantes del Consulado de México, quienes le otorgaban adelantos de la renta de alcabalas para el despacho de las flotas y las naos de China ${ }^{39}$. Por su parte, los mercaderes más poderosos lo auxiliaban para resolver las urgencias del erario más apremiantes ${ }^{40}$. En consecuencia, el virrey duque de Linares, al término de su mandato, se manifestó en contra de la competencia que imponían los peninsulares a los novohispanos en su propio espacio. El virrey consideraba que los flotistas debían vender a los miembros del consulado de México, sin poder tratar en otros mercados del virreinato, los cuales debían restringirse al servicio del "cuerpo de sus vasallos" que tan “considerable y principal” era en las Indias, en "donde no es gente el que no es mercader" 41 .

El virrey defendía los intereses de los principales mercaderes del consulado de México, quienes habilitaban la producción argentífera y realizaban tratos con los peruanos con el propósito de concentrar la plata que se producía en Nueva España y la que lle-

36 “Representación del Consulado de Sevilla al Consejo de Indias 30 de enero de 1714”. AGI, México 2501. Sobre el tráfico con Perú véase BONIALIAN, Op. Cit.

37 DELGADO RIVAS, Op. Cit., pp. 95, 96.

38 WALKER, Op. Cit., 1979, pp. 97, 100-102; STEIN, Op. Cit., 2002, pp. 169-172.

39 VALLE PAVÓN, Guillermina del "Servicios fiscales y financieros del consulado de comerciantes de la ciudad de México en los siglos XVII y XVIII”, en Gustavo Garza y Jaime Sobrino, coordinadores, Evolución del sector servicios en ciudades y regiones de México, México, El Colegio de México, 2009, pp. 95-117.

40 Pedro Sánchez de Tagle, líder de los montañeses que constituían una de las dos facciones en que se dividían el cuerpo mercantil, había ofrecido a Linares su respaldo durante la Guerra de Sucesión para subsanar la pérdida de la nave Almiranta de Barlovento y los fondos que conducía para los presidios, y cuando la flota había sido destruida por un huracán en Las Bahamas. "Instrucción del Duque de Linares, gobernador de la Nueva España, para su sucesor, con descripción geográfica y política de su gobierno e informe de los males que padecía, México, 22 de marzo de 1723” (Biblioteca Nacional -en adelante, BNMa-, (Madrid), mss, 2929, fs. 80, 127). Este documento esta fechado en 1723, cuando Linares dejó el gobierno de Nueva España en agosto de 1716 y murió en 1717.

41 Ibidem. fs. 7, 8v). 
gaba del virreinato andino. En esta forma aseguraban la supremacía en las transacciones que realizaban con Manila, Andalucía, otros reinos americanos y dentro del virreinato. Los cargadores que llegaban en las flotas y navíos de permiso competían permanecían por largos periodos en la capital y otros lugares del virreinato, lo que les daba oportunidad de competir con los mexicanos por la plata del diezmo y la que no había sido gravada, así como por otras mercancías americanas, como los tintes y el cacao.

La avasalladora competencia de los anglosajones obligó a la corona a introducir una serie de reformas para regularizar el tráfico de las flotas. En 1717 la Casa de Contratación y el Consulado de Cargadores de Indias se trasladaron de Sevilla a Cádiz ${ }^{42}$. En ese mismo año la municipalidad de Cádiz inició la construcción de su regia catedral ${ }^{43}$, posiblemente para dar gracias por la decisión real. A raíz del cambio de sede del cuerpo mercantil se mantuvo una diputación en Sevilla, lo que dio lugar a cierta "duplicidad” institucional. La representación sevillana estaba compuesta por dos delegados, que eran electos entre los cargadores matriculados, y tenía la función de tramitar los asuntos concernientes a los miembros sevillanos. En cuanto a la organización interna del Consulado, los tres oficios de jueces se distribuyeron entre los cargadores de Sevilla y Cádiz, tocando dos cónsules a los primeros y uno a los últimos. Asimismo se transformó el proceso electoral, de modo que de los treinta electores encargados de designar a los magistrados, veinte salían de la matrícula sevillana y diez de la gaditana ${ }^{44}$.

En 1718 el monarca prohibió el tráfico y el consumo de las sedas chinas, en atención a las denuncias del Consulado de Cargadores de Indias que, en 1714, había atribuido la escasa demanda del virreinato a los textiles asiáticos que competían con los españoles y ocasionaban la pérdida de la plata en el Oriente ${ }^{45}$. Sin embargo, ante las protestas de los comercios de México y Filipinas la restricción se levantó unos años después, luego de que los Manilos aceptaron un aumento en los gravámenes ${ }^{46}$.

Con el propósito de que la flota permaneciera en Nueva España el menor tiempo posible, en el mismo año de 1718 se ordenó que la feria se realizara en Jalapa, población ubicada a veinte leguas de Veracruz, en donde los españoles no podían permanecer por mucho tiempo a causa de su clima malsano. De acuerdo con la normatividad de la feria, una vez que los diputados de los comercios de España y México llegaran a un acuerdo sobre los precios, se tenían que vender todas las mercancías en un periodo aproximado de seis meses. De este modo se pretendía acabar con la costumbre de despachar las mercaderías “al por menor y al fiado”. Luego de haberse establecido que los comisionistas

42 GARCÍA-BAQUERO, Antonio, Cádiz y el Atlántico (1717-1778). El comercio colonial español bajo el monopolio gaditano, Cádiz, Diputación provincial de Cádiz, 1988, 2 vols. [1ª . Edición 1976], pp. 104-109.

43 Para iniciar la obra el municipio otorgó un donativo por 100,000 ducados y el resto de la obra fue financiada con los productos de un gravamen sobre el tráfico comercial. DOMÍNGUEZ ORTIZ, Op. Cit., p. 7.

44 GARCÍA-BAQUERO, Antonio, La Carrera de Indias: suma de la contratación y océano de negocios, Sevilla, Sociedad Estatal para la Exposición Universal de Sevilla / Algaida Editores 1992, pp. 81-83. La imposibilidad de los representantes de los cargadores de Cádiz para acceder al priorato limitó su influencia en la corporación, circunstancia que mantuvo la rivalidad entre las dos sedes del Consulado durante casi todo el siglo. BUSTOS, Op. Cit., pp. 54-57.

45 “Representación del Consulado de Sevilla al Consejo de Indias de 1714”. AGI, México 2501

46 WALKER, Op. Cit., p. 138; PÉREZ HERRERO, Pedro, “Actitudes del consulado de México ante las reformas comerciales borbónicas (1718-1765)”, en Revista de Indias, 44, núm. 174, pp. 466-488, 1984, pp. 109-111; DELGADO RIVAS, Op. Cit., pp. 100, 101. 
andaluces no se internaran en el virreinato ${ }^{47}$, el rey mandó que al término de la feria los factores andaluces podrían vender en “donde les pareciere”. El monarca cambio de parecer por influencia del Presidente de la Casa de la Contratación e Intendente de Marina, José Patiño, quien respaldaba a los cargadores andaluces, entre otras razones, por las contribuciones económicas que brindaban a sus proyectos ${ }^{48}$. La reglamentación de la feria quedó plasmada en el Real Proyecto de Flotas y Galeones de $1720^{49}$.

Las reformas introducidas en el Real Proyecto, desataron la lucha entre los cargadores que se consideraban españoles “antiguos” y los jenízaros, como se llamaba a los hijos de extranjeros naturalizados. La mayor inconformidad se generó por el establecimiento de la concesión de licencias para navíos sueltos ${ }^{50}$, porque podían otorgarse a personas que no estaban matriculadas en el Consulado de Indias. La posición de los extranjeros en Cádiz había mejorado a raíz de la Guerra de Sucesión, en especial la de los franceses por el apoyo que había brindado al pretendiente borbónico ${ }^{51}$. El Consulado de cargadores de Indias se propuso excluir de la Carrera de Indias a los jenízaros, porque se llevaban los mayores beneficios del monopolio hispano, en razón de su poder económico y financiero. Este se había puesto de manifiesto en la flota de 1717, en la que dieciocho individuos naturalizados habían cargado más que los setenta españoles “antiguos”. La diputación del cuerpo mercantil en Cádiz, en 1720 solicitó al rey que prohibiera la participación de los jenízaros en la Carrera de Indias por temor a que desplazaran a los “viejos” españoles en su papel de intermediarios ${ }^{52}$.

El comercio en Nueva España también se veía afectado por la normalización de los buques de "registro". Aunque éstos sólo podían destinarse a regiones secundarias a las que no llegaba la flota ${ }^{53}$, los que se dirigían a Campeche, Tabasco, Honduras, Santo Domingo y La Habana traficaban en Veracruz. Por este motivo, el Consulado de México había pedido que se suprimieran desde $1713^{54}$.

En la primera feria que se realizó en Jalapa, en 1721, los delegados de los comercios de Cádiz y México no llegaron a un convenio sobre los precios, por lo que los almaceneros realizaron compras mínimas ${ }^{55}$. En mayo de 1722 el monarca ordenó anular la feria, cuando prácticamente la mitad de la carga de la flota había quedado sin vender, y confirmó a los peninsulares la libertad para vender donde les conviniera ${ }^{56}$. Los

47 “Real orden, 20 de marzo 1718”, en REAL DÍAZ, José Joaquín, “Las ferias de Jalapa”, en Las ferias comerciales de Nueva España, México, Instituto Mexicano de Comercio Exterior, 1959, pp. 147- 148.

48 Kuethe, Allan J. "El fin del monopolio: los Borbones y el Consulado andaluz”, en VILA ViLar, Enriqueta; Allan J. KuETHE (eds.). Relaciones de poder y comercio colonial: nuevas perspectivas. Sevilla. Escuela de Estudios Hispano-americanos / Texas-Tech University, 1999, pp. 36-38, 41.

49 Capítulo 10 de la real cédula del 28 de septiembre de 1720. AGN, Reales cédulas, v. 41-50.

50 BUSTOS, Op. Cit., pp. 167, 168.

51 Idem.

52 GARCÍA-BAQUERO, Op. Cit., pp. 122-123; BUSTOS, Op. Cit., pp. 168-170.

53 GARCÍA-BAQUERO, Op. Cit., pp. 167-168.

54 “Representación del consulado de México al duque de Linares 1713”, AGI, México 2501.

55 El consulado planteó que sus miembros carecían de dinero para "levantar” una flota de veinte navíos, cuando el rey "solo había ofrecido siete”. Del Consulado a su apoderado Pedro Cristóbal de Reinoso, 16 de mayo de 1721. AGN, AHH, 2025, f 10v.

56 Se hace referencia a la real orden del 16 de mayo de 1722 en Inventario cedulas. AGN, AHH, 599-2. 
españoles “antiguos” se quejaron en el Consulado de Cargadores de Indias porque de los quince millones de pesos a que ascendía el total de la carga, sólo tres iban a su cargo. En Nueva España convencieron al comandante de la flota que los jenízaros tenían prohibido participar en la Carrera de Indias por ser extranjeros, o hijos de éstos, por lo que fueron obligados a regresar en el mismo convoy, dejando sus mercancías a cargo de los “viejos” españoles. Entonces, cuarenta y uno de los setenta y dos encomenderos se internaron en el virreinato para contratar ${ }^{57}$. Luego de varios años de lucha, en 1729, los cargadores de Sevilla consiguieron licencia para elaborar una lista de los comerciantes habilitados para el comercio con Hispanoamérica, de la que excluyeron a los hijos y nietos de extranjeros nacidos en España ${ }^{58}$.

En 1722 el Consulado de México, con el apoyo del virrey marqués de Casafuerte, mandó al soberano una representación en la que atribuyó los quebrantos que padecía el comercio de Nueva España a los encomenderos que permanecían en el virreinato. Suplicó que los “gachupines” no salieran de Jalapa para evitar que compraran a otros cargadores y trataran con mercancías orientales, del reino y de otras provincias americanas. Asimismo se manifestó en contra del arribo irregular de navíos sueltos, porque impedían hacer grandes compras ante la amenaza de que el mayor suministro de un producto abatiera su precio, y suplicó que sólo se dieran licencias a buques que hicieran la travesía a Veracruz en grupos de cinco o seis ${ }^{59}$. El cuerpo mercantil se esforzaba por conservar el monopolio de la distribución de bienes europeos en el virreinato; sin embargo, sus miembros enviaban capitales a Cádiz para que se invirtieran en créditos a riesgo de $\operatorname{mar}^{60}$.

En el mismo año de 1722 el consulado de México se esforzaba porque se anulara la autorización para que los ingleses penetraran en Nueva España. Con dicho objetivo presentó un memorial impreso en la corte real, en el que explicó que la concesión otorgada a la Compañía real de Inglaterra daría lugar a que sus factores acudieran a las poblaciones y reales de minas "a rescatar las platas y oros"61, y se los llevarían "sin quintar a su tierra”, hecho que unido a la exención de derechos y el contrabando que realizaban ocasionaría elevadas pérdidas al erario ${ }^{62}$. En esta forma, el cuerpo mercantil puso de manifiesto que su oposición a que los comerciantes ingleses, y peninsulares, penetraran en Nueva España buscaba impedir que compitieran por los metales preciosos, en espe-

57 REAL DÍAZ, Op. Cit., pp. 36-39; WALKER, Op. Cit., pp. 139, 140, 149-151.

58 La autorización mencionada se oponía a las órdenes dictadas en 27 de septiembre de 1725 y en 14 de febrero de 1726, que reconocían que los mencionados vasallos eran españoles. GARCÍA-BAQUERO, Op. Cit., pp. 122-126; BUSTOS, Op. Cit., pp. 168-170.

59 Representación del Consulado de México, 16 de noviembre de 1722. AGN, AHH, 269-2.

60 En 1723 el Consulado pagó en México cerca de 110,000 pesos en escrituras por dicho concepto. Del Tribunal del Consulado a su apoderado Pedro Cristóbal de Reinoso Mendoza, México, 15 de noviembre de 1723. AGN, AHH, 2025, f. 49 v.

61 En el asiento de esclavos se había establecido que los ingleses podían obtener en pago de dicha mercancías “dinero, lingotes de plata u oro, frutas y productos”. STEIN, Op. Cit., p. 172.

62 De acuerdo con el consulado, los ingleses realizarían su objetivo en "los reinos de minas de Pachuca, Guanajuato, San Luis, Zacatecas y provincia de Guadalajara”. Del tribunal del consulado a su apoderado Pedro Cristóbal de Reinoso. México, septiembre 22 de 1722. AGN, AHH, 2025, fs. 42, 43. 
cial por los que no pagaban derechos ${ }^{63}$. Muy probablemente también trataban de evitar que trataran con los peruanos que intercambiaban plata andina y cacao de Guayaquil por manufacturas y otros bienes europeos ${ }^{64}$.

La flota de 1723 llegó a Veracruz unas semanas antes del arribo del navío de permiso inglés, por lo que los comisionistas andaluces pudieron vender gran parte de sus mercancías. A principios de 1724 las ventas de los factores peninsulares cayeron drásticamente, junto con los precios, como consecuencia de la llegada de la Nao de China y el navío inglés que desembarco ilegalmente más de mil toneladas de mercancías ${ }^{65}$. El consulado de la colonia francesa establecida en Cádiz planteó con asombro que la carga introducida por el navío de permiso inglés representaba, cuando menos, la mitad de la que llevaba la flota, si no es que la sobrepasaba ${ }^{66}$. Los británicos habían obtenido licencia real para internarse en el virreinato, por lo que el Consulado de México, en 1722, había presentado al rey un memorial, en el que explicó que la concesión otorgada a los anglosajones les permitiría acudir a las poblaciones mineras a rescatar metales para llevarlos “sin quintar a su tierra”, hecho que unido a la exención de derechos y el contrabando que realizaban, ocasionaría al real erario pérdidas elevadas ${ }^{67}$.

En noviembre de 1723, el Consulado de México presentó al soberano otro memorial en el que pidió que los británicos se limitaran a vender en el puerto de Veracruz y solicitó al Consulado de Cádiz que respaldara su demanda ${ }^{68}$. La representación consular fue promovida por el Presidente del Consejo de Indias, cargo que entonces desempeñaba el marqués de Valero, quien había sido virrey de Nueva España de 1716 a 1722. En marzo de 1724, el rey derogó la autorización dada a los anglosajones para adentrarse en el virreinato ${ }^{69}$. Sin embargo, el bando que mandó a los factores ingleses salir de Nueva España se publicó diez meses después de su llegada, por lo que extrajeron grandes cantidades de plata ${ }^{70}$. Ante la disminución de la demanda en el virreinato, el Consulado de Cádiz pidió que se pospusiera el envío del siguiente convoy, pero como no había forma de impedir la salida del navío inglés, la flota salió en $1725^{71}$.

63 Aun cuando el derecho del quinto había sido sustituido por el diezmo, en Zacatecas en 1716 y en el resto del virreinato en 1723, (PÉREZ HERRERO, Pedro, Plata y libranzas. La articulación comercial del México borbónico, México, El Colegio de México, 1988, pp. 139, 140), es muy probable que los comerciantes siguieran evadiendo el pago del diezmo con la plata de fuego que era difícil de fiscalizar porque no requería de azogue.

64 Véase al respecto BONIALIAN, Op. Cit.

65 WALKER, Op. Cit., pp. 167, 168.

66 BUSTOS, Op. Cit., p. 361.

67 REAL DÍAZ, Op. Cit., pp. 47, 48, 53; WALKER, Op. Cit., 1979, pp. 165, 166. Del tribunal del Consulado a su apoderado Pedro Cristóbal de Reinoso. México, septiembre 22 de 1722. AGN, AHH, 2025, fs. 42, 43.

68 Del Consulado de México a Pedro Cristóbal de Reinoso y al Consulado de Cádiz, México 15 de noviembre de 1723. AGN, AHH, 2025. El Consulado de Cádiz había planteado al rey la misma demanda en octubre de 1724. REAL DÍAZ, Op. Cit., p. 54.

69 En reconocimiento a la valiosa intercesión del marqués de Valero, el consulado de México le hizo llegar un lote de las medallas con las que conmemoró la coronación de Luis I, nueve en oro, para que entregara ocho a "las personas reales" y conservara una, y cien de plata. Del Consulado marqués de Valero, 15 de agosto de 1724. AGN, AHH, 2025.

70 Del Consulado a Pedro Cristóbal de Reinoso, México, 12 de agosto de 1724. AGN, AHH, fs. 54 y v.

71 REAL DÍAZ, Op. Cit., pp. 63-64; WALKER, Op. Cit., pp. 168-171. 
Los encomenderos llegaron a Nueva España con autorización para vender en donde les conviniera, luego de que el Consulado de Cádiz había manifestado su temor de que los diputados del comercio de México a la feria de Jalapa se resistieran a llegar a un convenio sobre los precios ${ }^{72}$. Poco después arribó el buque inglés, cuyos factores se internaron en el virreinato para vender esclavos y comerciar de manera subrepticia ${ }^{73}$. Ante la competencia de los géneros ingleses y orientales, la flota tuvo que regresar a Cádiz dejando a varios peninsulares con más de la tercera parte de la carga ${ }^{74}$. El inicio de hostilidades con Gran Bretaña, a mediados de 1726, dio lugar a la confiscación del navío de permiso y el resto de los bienes de los anglosajones, quienes quedaron al margen de la competencia por algunos años ${ }^{75}$.

Los requerimientos de la guerra contra Gran Bretaña dieron lugar a que, en el mismo año de 1726, el monarca demandara al virrey marqués de Casafuerte el envío de grandes caudales para la defensa del Caribe y el intento por recuperar Gibraltar. El marqués solicitó al Consulado un nuevo préstamo por un millón de pesos a cuenta de la renta de las alcabalas. Ante la escasez de liquidez que padecían los mercaderes de México por la reciente partida de la flota, únicamente pudieron aportar el 40\% del empréstito, por lo que solicitaron las aportaciones de los flotistas. Como había sucedido en 1706, los diputados del comercio de España se negaron a contribuir a para las urgencias del monarca, aun cuando se "les hizo presente la obligación que tenían... cuando eran tan conocidas las utilidades que avanzaban en las muchas tiendas que tenían sus almacenes y negociaciones, no sólo en la ciudad, sino en todo el reino”. En 1727, el prior y los cónsules lograron reunir el millón de pesos requerido tomando dinero a premio de individuos y corporaciones eclesiásticas, así como de los juzgados que resguardaban los capitales de los litigios que se encontraban en proceso $^{76}$.

Luego de haber prestado tan importante servicio financiero, en 1728 el Consulado de México logró que el marqués de Casafuerte modificara la normatividad de la feria a favor de sus miembros. El virrey estableció que si los diputados de España y México no llegaban a un acuerdo sobre los precios, él resolvería lo conveniente, prohibió a los peninsulares vender las mercancías rezagadas fuera de Jalapa y, para que regresaran en la misma flota, dispuso que los almaceneros las compraran a precio de feria o las recibieran en encomienda ${ }^{77}$. Con base en esta nueva reglamentación la corona pudo garantizar el funcionamiento de las ferias. En la que se efectuó en Jalapa de 1729

72 Real cédula del 14 de abril de 1725. AGN, Reales cédulas, v. 45-10, fs. 20-22.

73 Dicha licencia se había dado por cédula del 28 de julio de 1725. Del Consulado al marqués de Valero, al Consulado de Cádiz y a Juan Joseph de Reinoso, México, 7 de mayo y 22 de junio de 1726. AGN, AHH, 2025, fs. 85-90, 102.

74 WALKER, Op. Cit., pp. 172-174.

75 Del Consulado de México al de Cádiz y a su apoderado, Pedro Cristóbal de Reinoso, 20 de agosto de 1726. AGN, AHH, 2025, fs. 101 v, 102, 106 v. WALKER, Op. Cit., pp. 173-174.

76 Juntas de comercio en virtud de decreto del excmo. sr. marqués de Casafuerte, virrey de esta Nueva España, sobre el empréstito de un millón de pesos. AGN, AHH, 213-3, fs. 1v-41.

77 Se estableció “que no se extravíen las ropas y géneros que llevaren [las flotas], ni los comerciantes que fueren en ellas, que es lo que conduce a asegurar el buen éxito de las ferias”. Sólo en caso de que el comercio de México no dispusiera del monto necesario para adquirir los rezagos, los flotistas serían autorizados a desplazarse al interior de Nueva España. "Real Cédula de 2 de abril de 1728”, en REAL DÍAZ, Op. Cit., documento 2, p. 150. 
las negociaciones sobre los precios de las mercancías y las ventas se llevaron a cabo sin ningún inconveniente. Sin embargo, las autoridades no consiguieron regularizar el calendario de las flotas. A partir de entonces quedaron establecidos los límites territoriales para que los comisionistas andaluces y los mercaderes de México negociaran las mercaderías de Castilla y Europa en Nueva España. Los primeros debían restringir sus ventas a la feria de Jalapa, quedando a cargo de los almaceneros su distribución en el interior del virreinato.

En la feria que se realizó en 1732-1733 nuevamente se padeció la competencia del navío inglés, por lo que flota tuvo que retornar dejando rezagos por valor aproximado de siete millones de pesos. Las demandas del Consulado de Cádiz para que se autorizara a los encomenderos a penetrar en el virreinato no fueron atendidas, por lo que tuvieron que permanecer en Jalapa a la espera de compradores. ${ }^{78}$ En 1735 el Consulado de Cargadores de Indias consiguió que se prohibiera a los almaceneros remitir caudales a Cádiz para negociar por su propia cuenta. ${ }^{79}$ En adelante los mercaderes de México tuvieron que recurrir a los cargadores peninsulares para adquirir los bienes europeos. De este modo, la monarquía acabó con el privilegio que habían tenido los mercaderes de México para adquirir en Cádiz los bienes europeos.

\section{Consideraciones finales}

En las últimas décadas del siglo XVII las autoridades reales se esforzaron por regularizar la Carrera de Indias a fin de incrementar el tráfico mercantil y los ingresos fiscales. Con este fin se trasladó la cabecera de las flotas de Sevilla a Cádiz y se mandó establecer una feria de flotas en el puerto de Veracruz para agilizar el retorno de los convoyes. Entonces las flotas sólo satisfacían parte la demanda de Nueva España, en razón del importante abasto de bienes orientales y el contrabando que realizaban las potencias europeas, por lo que los almaceneros podían presionar con éxito a los flotistas para que redujeran los precios. El monopolio comercial y el contrabando (comercio legal e ilícito) se complementaban en beneficio de los mercaderes de México, que eran los principales compradores de los bienes externos debido al control que ejercían sobre la plata. En 1683, 1706 y 1708 se intentó sin éxito realizar la feria en Veracruz, porque los representantes de los almaceneros se resistieron a llegar a un acuerdo con diputados de los cargadores peninsulares los sobre los precios de las mercancías. En consecuencia los flotistas continuaron desplazándose a la ciudad de México y otros lugares del virreinato para tratar los bienes europeos.

La participación legal de los ingleses en el mercado de Nueva España restó competitividad al comercio de flotas, por lo que la corona tuvo que realizar una serie de reformas. Las más importantes fueron el traslado de la administración de la Carrera

\footnotetext{
78 WALKER, Op. Cit., p. 237; DELGADO RIVAS, Op. Cit., pp. 126, 127. Tampoco fue atendida la propuesta planteada por el Presidente de la Casa de contratación, quien propuso en 1732, que se autorizara a los flotistas a internarse en el virreinato para vender sus rezagos y que los precios de la feria se negociaran entre dos diputados del comercio de México, uno de Puebla y tres diputados peninsulares. ARCILA FARÍAS, Eduardo, Reformas económicas del siglo XVIII en Nueva España, t. 1, México, Secretaría de Educación Pública, 1974, p. 89-91.

79 REAL DÍAZ, Op. Cit., pp. 103-104; PÉREZ HERRERO, “Actitudes”, Op. Cit., p. 130.
} 
de Indias a Cádiz y el establecimiento de la feria en el pueblo de Jalapa, ubicado cerca del puerto de Veracruz. Las transformaciones en la normatividad del comercio con el virreinato dieron lugar a que desatara la pugna entre los cargadores que se autodefinían como "españoles viejos" y los descendientes de extranjeros que eran conocidos como los jenízaros. Por su parte, los mercaderes de México sabotearon la feria al oponerse a llegar a un acuerdo sobre los precios y limitar sus compras. Al ver que el monarca no cejaría en su empeño de realizar dicha feria, se opusieron a que los cargadores penetraran en el virreinato para impedir que compitieran por la plata, los bienes orientales, el cacao, los tintes y otros productos americanos. El Consulado de México se valió de su poder financiero para lograr que el virrey limitara a los flotistas a vender en Jalapa y reservara a sus miembros la distribución de los bienes europeos en el interior de Nueva España. Sólo entonces accedieron a negociar en Jalapa. Al cabo de unos años, el Consulado de Cargadores de Indias consiguió que se prohibiera a los mexicanos enviar caudales a Cádiz para negociar de manera autónoma. 
